\title{
Production improvement in gas condensate reservoirs by wettability alteration, using superamphiphobic titanium oxide nanofluid
}

\author{
Pouriya Esmaeilzadeh ${ }^{1}$, Mohammad Taghi Sadeghi ${ }^{1, *}$, and Alireza Bahramian ${ }^{2}$ \\ ${ }^{1}$ Chemical Engineering College, Iran University of Science and Technology (IUST), Narmak, Tehran, Iran \\ ${ }^{2}$ Institute of Petroleum Engineering, University of Tehran, Tehran, Iran
}

Received: 9 October 2016 / Accepted: 28 August 2018

\begin{abstract}
Many gas condensate reservoirs suffer a loss in productivity owing to accumulation of liquid in nearwellbore region. Wettability alteration of reservoir rock from liquid-wetting to gas-wetting appears to be a promising technique for elimination of the condensate blockage. In this paper, we report use of a superamphiphobic nanofluid containing $\mathrm{TiO}_{2}$ nanoparticles and low surface energy materials as polytetrafluoroethylene and trichloro $(1 \mathrm{H}, 1 \mathrm{H}, 2 \mathrm{H}, 2 \mathrm{H}$-perfluorooctyl)silane to change the wettability of the carbonate reservoir rock to ultra gas-wetting. The utilization of nanofluid in the wettability alteration of carbonate rocks to gas-wetting in core scale has not been reported already and is still an ongoing issue. Contact angle measurements was conducted to investigate the wettability of carbonate core plugs in presence of nanofluid. It was found that the novel formulated nanofluid used in this work can remarkably change the wettability of the rock from both strongly water- and oil-wetting to highly gas-wetting condition. The adsorption of nanoparticles on the rock and formation of nano/submicron surface roughness was verified by Scanning Electron Microscope (SEM) and Stylus Profilometer (SP) analyses. Using free imbibition test, we showed that the nanofluid can imbibe interestingly into the core sample, resulting in notable ultimate gas-condensate liquid recovery. Moreover, we studied the effect of nanofluid on relative permeability and recovery performance of gas/water and gas/ oil systems for a carbonate core. The result of coreflooding tests demonstrates that the relative permeability of both gas and liquid phase increased significantly as well as the liquid phase recovery enhanced greatly after the wettability alteration to gas-wetting.
\end{abstract}

\section{Introduction}

In gas condensate reservoirs, when the pressure of reservoir drops below the dew point, a condensate phase forms and flows along with the gas phase in the reservoir as its saturation reaches or exceeds the critical condensate saturation. The condensate will accumulate gradually and become trapped in near wellbore region. This accumulation of liquid which is known as condensate banking or condensate blockage, results in reduced gas and condensate production rates and sharp lowered well deliverability $[1,2]$. Condensate can be mobilized from formation around the wellbore by either increasing the drawdown pressure (viscous forces) or lowering capillary pressure. The capillary pressure $\left(\mathrm{P}_{C}\right)$ is proportional to contact angle $(\theta)$, interfacial tension $(\sigma)$ and reversely proportional to pore size $(r)$, according to Young-Laplace equation.

\footnotetext{
* Corresponding author: sadeghi@iust.ac.ir
}

$$
\mathrm{P}_{C}=\frac{2 \sigma \cos \theta}{r}
$$

Capillary pressure can be decreased by either reducing the interfacial tension or increasing the contact angle through wettability alteration. Solvents have been used to eliminate condensate blockage from gas wells by reducing interfacial tension however, their effectiveness is reported to be temporary [3, 4]. Li and Firoozabadi [5] were the first who suggested to enhance the gas well deliverability by permanent wettability alteration of near wellbore region from strong liquid-wetness to preferential gas-wetness. They demonstrated the idea experimentally by measuring contact angle and performing imbibition test on cores treated with fluorochemical surfactant/polymer at room temperature. Tang and Firoozabadi $[6,7]$ verified that the fluoropolymer chemicals were stable up to $93{ }^{\circ} \mathrm{C}$ and could successfully increase liquid mobility. The work was extended by Fahes and Firoozabadi [8] to a higher temperature of $140{ }^{\circ} \mathrm{C}$ by examining of several fluorochemical with various functional groups. Noh and Firoozabadi [9] studied the 
effect of wettability alteration to intermediate gas-wetting in water/gas two-phase flow. The results demonstrated the effectiveness of wettability alteration from improved gas relative permeability in nitrogen-water system.

Following the researches of Firoozabadi and his group members, other researchers also made contributions toward mitigating liquid blockage by modifying the wettability of various rock types to intermediate gas-wetting. Kumar et al. $[10,11]$ reported enhancement of the gas and condensate relative permeabilities for Berea and sandstone reservoir cores by a factor of 2-3 over the temperature range of $145-275^{\circ} \mathrm{F}$, using a nonionic surfactant soluble in methanol-water mixture. Xie et al. [12] changed the wettability of a water-wet sandstone core to intermediate gas-wetness, employing a water-soluble chemical surfactant. Their experimental data showed an increase in gas phase deliverability after the chemical treatment. Li et al. [13] developed a costeffective fluorocarbon surfactant which is stable at a temperature of $170{ }^{\circ} \mathrm{C}$ and a salinity of about $70000 \mathrm{ppm}$. They showed the chemical is able to raise the relative permeability of gas- and water-phase. Feng et al. [14] and Sharifzadeh et al. [15] also reported the preparation of a new fluoroacrylate copolymer emulsion and a polymeric surfactant coating, respectively, capable of increasing the liquid repellency of rock surfaces.

More recently, the use of nanoparticles has been suggested by some researchers as an effective agent for wettability alteration to gas-wetting. Nanoparticles are very active materials with a high tendency to form nanostructured surfaces, which can strongly affect the wetting property of solids. Mousavi et al. [16] succeeded to change the wettability of a limestone gas reservoir core from strongly liquid-wetting to intermediate gas-wetting by preparing fluorinated silica nanoparticles with an average diameter of $80 \mathrm{~nm}$. Aminnaji et al. [17] experimentally studied the use of a nanofluid containing organofluorine and silicon-based nanoparticles with reasonable capability to change the wettability of the carbonate and sandstone rocks to intermediate gas-wet state. Recently, we have reported for the first time on achieving the wettability alteration of strongly liquid-wet carbonate rocks to ultra gas-wet state using novel $\mathrm{TiO}_{2}, \mathrm{SiO}_{2}$ and $\mathrm{CNT}$ nanofluids by performing several small-scale slab tests [18].

In the present work, we study in detail the practical efficiency of the super liquid-repellent $\mathrm{TiO}_{2}$ nanofluid through a set of experiments in core scale, which represents better the reservoir conditions. First, we demonstrated wettability alteration of both water-wet and oil-wet carbonate cores to gas-wet state using contact angle measurements, with rock surface being characterized by use of SEM images and SP analysis. Next, the impact of wettability alteration on the amount of recovered gas-condensate liquid was investigated using spontaneous imbibition test. Moreover, coreflooding tests were carried out to study the ability of the nanofluid in flow tests. Accordingly, relative permeability data of gas and liquid (gas-condensate or brine) and the amount of recovered liquid were measured and being compared with and without wettability alteration to gas-wetting. Finally, the effect of initial gas-condensate saturation on treatment efficiency of nanofluid was investigated.

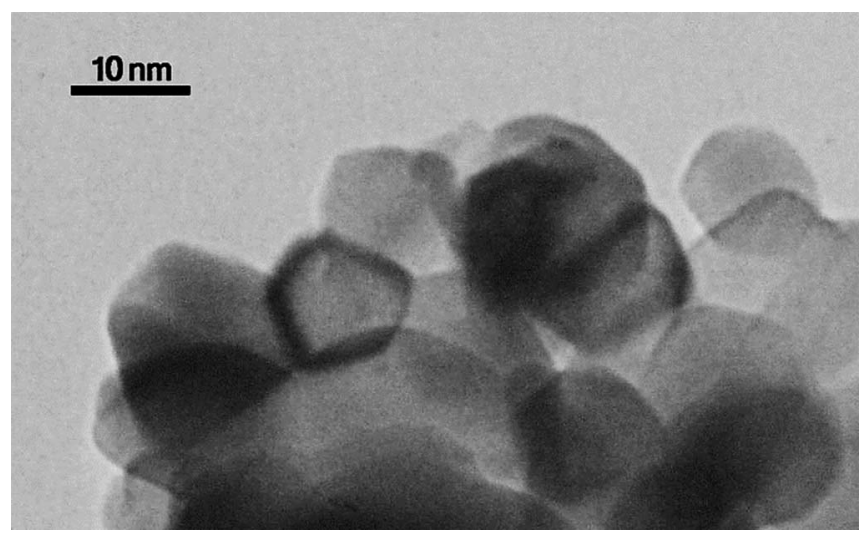

Fig. 1. TEM image of synthesized $\mathrm{TiO}_{2}$ nanoparticles.

\section{Materials and methods}

\subsection{Fabrication of superamphiphobic $\mathrm{TiO}_{2}$ nanofluid}

First, $\mathrm{TiO}_{2}$ nanoparticles were synthesized using sol-gel methods that consist of acidic hydrolysis of Tetraethyl orthotitanate (TEOT, $\mathrm{Ti}\left(\mathrm{OC}_{2} \mathrm{H}_{5}\right)_{4},>99 \%$, Merck) in alcoholic medium. To achieve this, $26 \mathrm{~g}$ of TEOT was dissolved in a mixture of ethanol $\left(\mathrm{C}_{2} \mathrm{H}_{5} \mathrm{OH}\right.$, Merck $)$ and isopropyl alcohol $\left(\mathrm{C}_{3} \mathrm{H}_{8} \mathrm{O}\right.$, Merck) and magnetically stirred for 30 min. $2 \mathrm{~mL}$ of ethylene diamine $\left(\mathrm{C}_{2} \mathrm{H}_{8} \mathrm{~N}_{2}\right.$, Merck $)$ was added gently to this solution and then it was hydrolyzed by drop-wise addition of nitric acid $65 \%\left(\mathrm{HNO}_{3}\right.$, Merck $) /$ water solution, under vigorous stirring for $1 \mathrm{~h}$ at 70 $80^{\circ} \mathrm{C}$. After refluxing for $2-3 \mathrm{~h}$, the obtained solution (with acidic $\mathrm{pH}$ ) was quenched rapidly and then filtered, washed and dried in oven at $80{ }^{\circ} \mathrm{C}$. Finally, the resultant product was calcined at $800{ }^{\circ} \mathrm{C}$ for $6 \mathrm{~h}$ in a muffle furnace. We have demonstrated this procedure of synthesizing that leads to production of fine $\mathrm{TiO}_{2}$ nanoparticles with superhydrophobic and self-cleaning properties [18]. The sizes of the synthesized nanoparticles were determined to be $12-20 \mathrm{~nm}$, using Transmission Electron Microscopy (TEM) (Philips CM30) (Fig. 1).

In continue, superamphiphobic $\mathrm{TiO}_{2}$ nanofluid was fabricated using the synthesized nanoparticles and fluoro-containing materials. For this purpose, $\mathrm{TiO}_{2}$ nanoparticles, polytetrafluoroethylene (PTFE), ethanol and a mixture containing Trichloro $(1 \mathrm{H}, 1 \mathrm{H}, 2 \mathrm{H}, 2 \mathrm{H}$-perfluorooctyl)silane (PFOS, 97\%) were dissolved with mass ratio of 0.002:0.002:1:1. Next, the resultant solution was sonicated by ultrasonic homogenizer for 30-40 min and finally stirred for $1 \mathrm{~h}$ at $50{ }^{\circ} \mathrm{C}$ [19-22].

\subsection{Rocks and fluids}

Two cylindrical carbonate reservoir cores with diameter of about $3.8 \mathrm{~cm}$ were used in this study to perform imbibition and coreflooding tests. The cores were cleaned using a Soxhlet extraction apparatus where they were flushed with toluene and methanol for 24 and $72 \mathrm{~h}$, respectively. Next, the cores were dried at $80^{\circ} \mathrm{C}$ for $24 \mathrm{~h}$. The properties of the water-wet core samples are summarized in Table 1. 
Table 1. Properties of core samples.

\begin{tabular}{lcccc}
\hline Core No. & Diameter $(\mathrm{cm})$ & Length $(\mathrm{cm})$ & Porosity $(\%)$ & Permeability $(\mathrm{md})$ \\
\hline CC-1 & 3.79 & 5.76 & 18.7 & 2.5 \\
CC-2 & 3.8 & 4.67 & 19.2 & 9.7 \\
\hline
\end{tabular}

Moreover, two cylindrical core plugs with length of $3 \mathrm{~cm}$ and diameter of $3.79 \mathrm{~cm}$ were used in contact angle measurement tests. The core plugs were cut along radius using a trimming machine, from the core sample CC-1 which was initially $11.76 \mathrm{~cm}$ in length.

Normal decane $\left(\mathrm{C}_{10} \mathrm{H}_{22}\right.$, Merck, $\left.>99 \%\right)$ and a gas-condensate liquid sample from an Iranian gas condensate reservoir with 0.78 specific gravity and $1.28 \mathrm{cp}$ viscosity at $T=25^{\circ} \mathrm{C}$ were used as oil phase. Distilled water and $7 \mathrm{wt} \% \mathrm{NaCl}$ brine represent the aqueous phase. Air and nitrogen were used as gas phase in contact angle measurement and coreflooding test, respectively.

\subsection{Contact angle measurement}

In order to study the influence of the prepared $\mathrm{TiO}_{2}$ nanofluid on wettability alteration, the core plugs were fully submerged in nanofluids and aged in an oven at $80{ }^{\circ} \mathrm{C}$ for $48 \mathrm{~h}$ [18]. Then, the core plugs were dried at $80{ }^{\circ} \mathrm{C}$ prior to the contact angle measurement test. Sessile drop method was used for measuring the contact angle of aqueous and oil phases at room temperature in air medium. An accurate syringe was used to place a liquid drop of $\sim 5 \mu \mathrm{L}$ on the surface of the core plugs. Snapshots of the droplet image were taken by a microscopic camera under sufficient illumination of light source. The reported contact angle value for each droplet corresponds the average of 3-5 measurements at different positions on the solid surface.

\subsection{Characterization}

The surface morphology of carbonate core plugs was examined by Scanning Electron Microscope (SEM) (KYKY model EM3200), before and after wettability alteration. Stylus Profilometer (SP) (Dektak XT from Bruker) was used to study the surface topography and roughness of the treated and untreated core plugs. To prepare the rock for SP analysis, step technique was applied [23]. In this method, during the treatment process of rock by nanofluid a step was created using sticky paper by obstructing one piece of the rock surface. This allowed the nanoparticles to be adsorbed on the other part portion. At the end of the treatment process, the sticky paper was removed and the surface roughness of both treated and untreated parts was investigated by SP around the border region with area of $1.5 \mathrm{~mm} \times 0.2 \mathrm{~mm}$.

\subsection{Spontaneous imbibition test}

The impact of wettability alteration to gas-wetting on the amount of recovered gas-condensate liquid is investigated using a free imbibition test. To prepare a core for the test, the core sample CC-2 was put in coreflooding apparatus, first. The core was initially evacuated and saturated then by gas-condensate at a constant injection rate of $2 \mathrm{cc} /$ min. After that, the oil-saturated core was aged in gas-condensate at $80{ }^{\circ} \mathrm{C}$ for 14 days. Using Amott-Harvey cell, oil recovery was measured during free imbibition test. The saturated core sample was placed into the cell containing $\mathrm{TiO}_{2}$ nanofluid. As the nanofluid imbibes into the core sample, gas-condensate is coming out from the pores and floating into the volumetric buret. The process took place in an oven at $80{ }^{\circ} \mathrm{C}$ and the produced oil was measured versus time.

\subsection{Coreflooding test}

Fluid flow tests were carried out to evaluate the efficiency of the $\mathrm{TiO}_{2}$ nanofluid in wettability alteration to gas-wetting in core scale. Figure 2 shows a schematic diagram of the coreflooding setup. The apparatus is capable of resisting reservoir condition of temperature and pressure. The core sample is fixed inside the core holder covered with a Viton rubber sleeve. In order to avoid gravity effect, it is placed horizontally. An overburden pressure of 800 psig above the inlet pressure is applied on the core. The pressure drop across the core is measured by a differential pressure transducer (Rosemount 3051) and the corresponding data are recorded by a data acquisition system. The temperature of the system is kept at $80{ }^{\circ} \mathrm{C}$ during all tests, using an oven. A back pressure regulator is used to control the outlet flowing pressure.

In this study, gas/oil and gas/water relative permeabilities were measured by unsteady state method in core CC-1. Before wettability alteration, the core was saturated with liquid (brine or gas-condensate) by vacuuming to get rid of the air. To make sure a full saturation, the core was maintained in core holder at high pressure of $3000 \mathrm{psig}$ for two weeks. The absolute permeability to brine was determined afterward. Next, the nitrogen was injected at a constant pressure to displace the liquid. The injection pressure gradient was chosen high enough to mitigate the capillary end-effect and reducing the wetting phase saturation at the outlet of the core. This parameter is defined as $\Delta p^{*}$ in the coreflooding experiments. The amount of produced liquid and gas versus time was recorded until no more liquid was recovered. The gas-liquid relative permeability was calculated subsequently, using the Toth method [24] (See the procedure of calculations in the Appendix). The core was cleaned and dried at the end of each test.

After performing the evaluation testing in the untreated core, we conducted the wettability alteration tests. To alter the wettability of the core to gas-wetness, the dry core was 


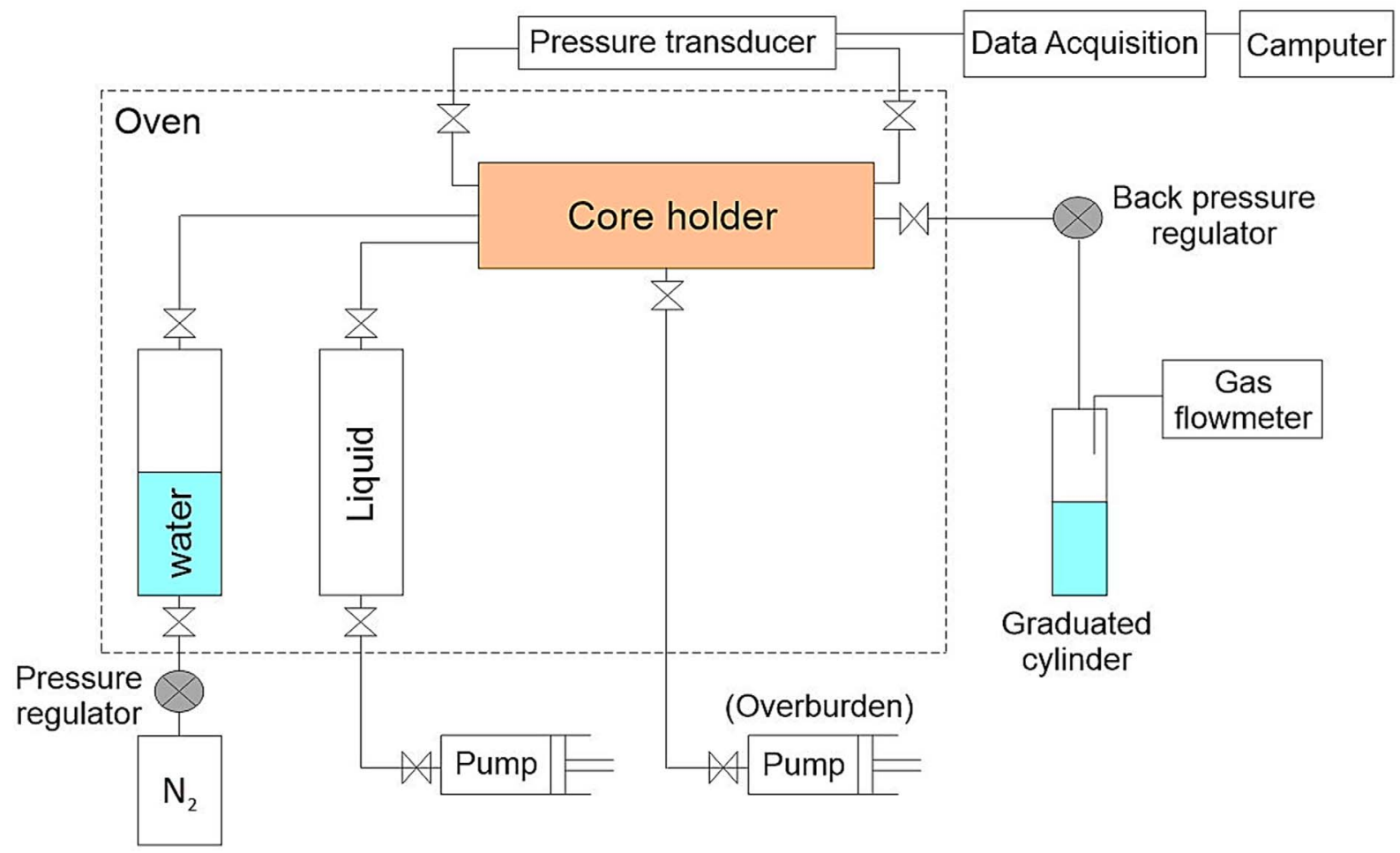

Fig. 2. Schematic of apparatus for coreflooding experiments.
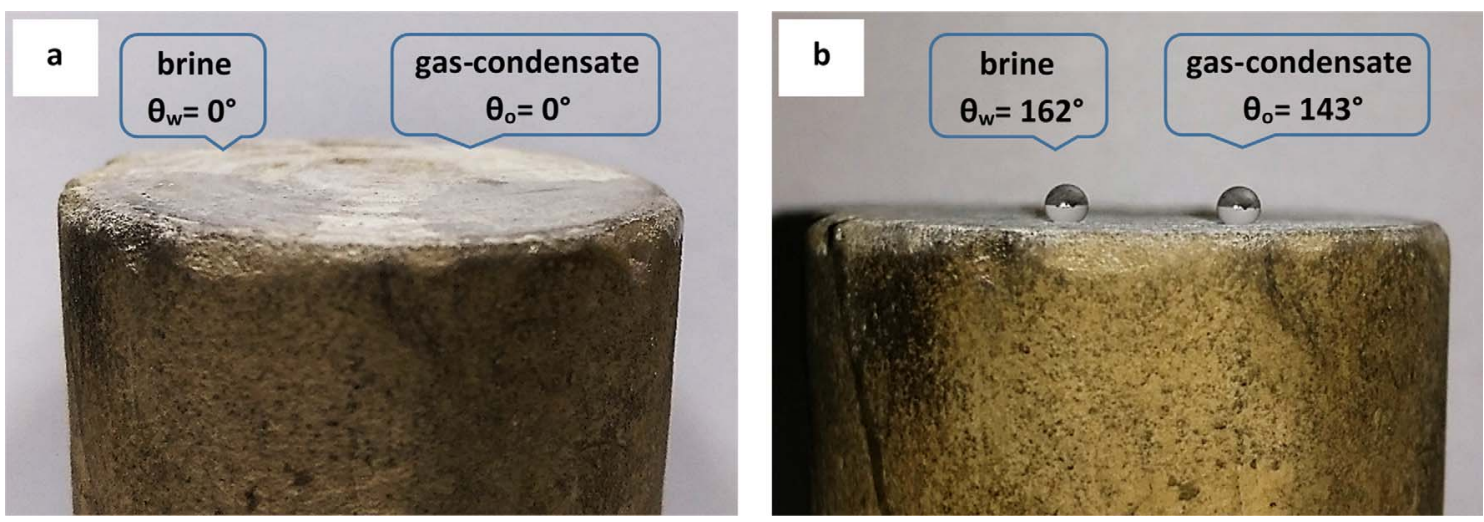

Fig. 3. Contact angle of brine and gas-condensate on surface of (a) untreated and (b) treated carbonate core plug.

saturated with nanofluid after being evacuated. Three to four Pore Volumes (PV) of nanofluid were injected at a fixed flow rate of $2 \mathrm{cc} / \mathrm{min}$, followed by aging for $48 \mathrm{~h}$ at $80{ }^{\circ} \mathrm{C}$ and 3000 psig. To drain the extra nanofluid after aging, $5 \mathrm{PVs}$ of brine were injected to the core, first and then it was evacuated for about $6 \mathrm{~h}$. At last, the core was drawn out of the core holder and dried in an oven at $80^{\circ} \mathrm{C}$.

After the core treatment process, brine (or gas-condensate) was injected to the core and the same tests to those conducted for untreated core were repeated to measure the gas-liquid relative permeability after the wettability alteration.

\section{Results and discussion}

\subsection{Contact angle measurements and surface characterization}

In order to examine the water and oil repellency of the fabricated nanofluid, contact angles of distilled water and brine as aqueous phase, and $n$-decane and gas-condensate as oil phase were measured on a strongly water-wet core plug. Before wettability alteration, both water and oil liquid drops imbibed into the core plug instantly after being placed on surface of the core. Hence, their corresponding 
contact angles were measured to be $0^{\circ}$. After the treatment of the core sample with nanofluid, the contact angles of distilled water, brine, $n$-decane and gas-condensate remarkably increased to $161^{\circ}, 162^{\circ}, 144^{\circ}$, and $143^{\circ}$, respectively. Considering these data, it can be deduced that the superamphiphobic $\mathrm{TiO}_{2}$ nanofluid has increased the water and oil contact angle to a much greater degree than the chemicals reported in the former studies $[5,8,9,13-17]$. As it is obvious from the results, no sensible difference could be perceived between the contact angle of distilled water and brine, and the contact angle of $n$-decane and gas-condensate as well. Furthermore, it can be deduced that the effectiveness of the nanofluid are not changed at very high salinity. Figure 3 shows the contact angle of brine and gas-condensate on surface of the carbonate core plug, before and after treatment with $\mathrm{TiO}_{2}$ nanofluid.

Two crucial factors which affect the wettability of a solid surface are known to be the surface morphology and surface energy [25-27]. Accordingly, a combination of enhancing the surface roughness and lowering the surface energy affords the super liquid repellency. Hence, the morphological characterization of the core surface structures was examined using SEM and SP techniques. Figure 4 displays the SEM images of the untreated and treated core plug surfaces. Comparing the surface of native core plug with surface morphology of the core aged in $\mathrm{TiO}_{2}$ nanofluid, one can see clearly the formation of sphere-like nanotextures on the microstructure core surface after the treatment. The average size of the nanostructures was measured about 20-50 $\mathrm{nm}$ in diameter.

Figure 5 shows the SP topography images for both untrated and treated core plug. As it is evident from the images, the core surface provides a primary roughness inherently. The original core plug exhibits a superhydrophilic and superoleophilic nature (i.e., contact angle of water and oil $=0^{\circ}$ ) due to presence of several valleys throughout the roughness. After treatment with nanofluid, nanoparticles adsorb on the core surface and develop a new roughness on the surface. Such a dual-roughened surface consisted of the micro-scaled core asperities (primary roughness) and a nanotuxtured layer (secondary roughness), similar to the structure of a lotous leaf [28], is capable of arising the superhydrophobicity (i.e., contact angle of water $=162^{\circ}$ ) owing to a lots of air get trapped into the cavities between the protrusions. Therefore, obeying the Cassie model [29], when a water drop is placed on the surface of the treated core plug, it only contacts the top of the protrusions and suspends spherically, according to a large water-air interface which prevents the drop from peneterating into the cavities.

In addition to surfuce roughness, fluorochemicals as PTFE and PFOS solution were employed to achieve oleophobicity (i.e., contact angle of gas-condensate $=143^{\circ}$ ) by lowering the surface energy. Several studied reported the proper influence of teflon (PTFE) on water and oil repellency of different substrates $[30,31]$. The surface free energy of teflon is known to be $18.5 \mathrm{mN} \mathrm{m}^{-1}$ [32]. Besides, the high content of $-\mathrm{CF}_{3}$ and $-\mathrm{CF}_{2}$ groups presence in PFOS, introduced it as a chemical with a very low surface energy. It is noteworthy that $-\mathrm{CF}_{3}$ terminated surfaces
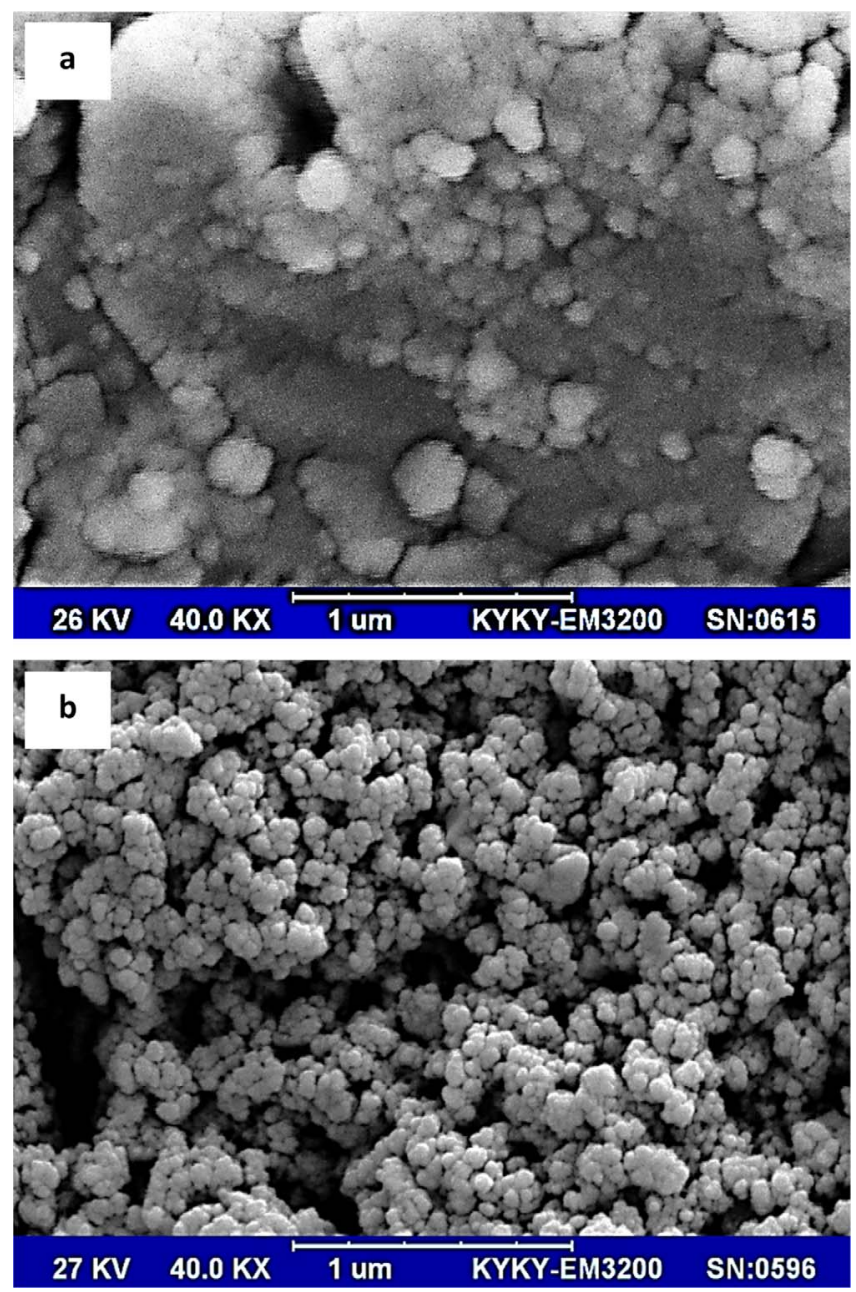

Fig. 4. SEM images of carbonate core plug (a) before and (b) after treatment with the $\mathrm{TiO}_{2}$ nanofluid.

possess the lowest surface free energy $\left(\sim 6 \mathrm{mN} \mathrm{m}^{-1}\right)$ followed by $-\mathrm{CF}_{2}$ as the next lowest [32-35].

\subsection{Effect of initial wettability state on brine and gas-condensate contact angles}

In order to examine the effect of initial wettability state on wettability alteration to ultra gas-wetting by $\mathrm{TiO}_{2}$ nanofluid treatment, a clean and dry core plug was aged for two weeks in the gas-condensate at $80^{\circ} \mathrm{C}$. After cooling, the sample was rinsed and dried at $80{ }^{\circ} \mathrm{C}$ for $24 \mathrm{~h}$. The oil-wetting state of the dried core plug was evaluated by measuring the gas-condensate/water/rock contact angle in water medium. A strong oil-wet condition for the core sample was indicated, since the gas-condensate drop completely spred out on the core surface.

Contact angles of $90^{\circ}$ and $0^{\circ}$ were recorded for brine and gas-condensate, respectively, for the untreated oil-wet core plug. After treatment with nanofluid, the brine and gascondensate contact angles increased to $162^{\circ}$ and $120^{\circ}$, respectively. Hence, for the treated core samples, the obtained superhydrophobicity is independent of the core 

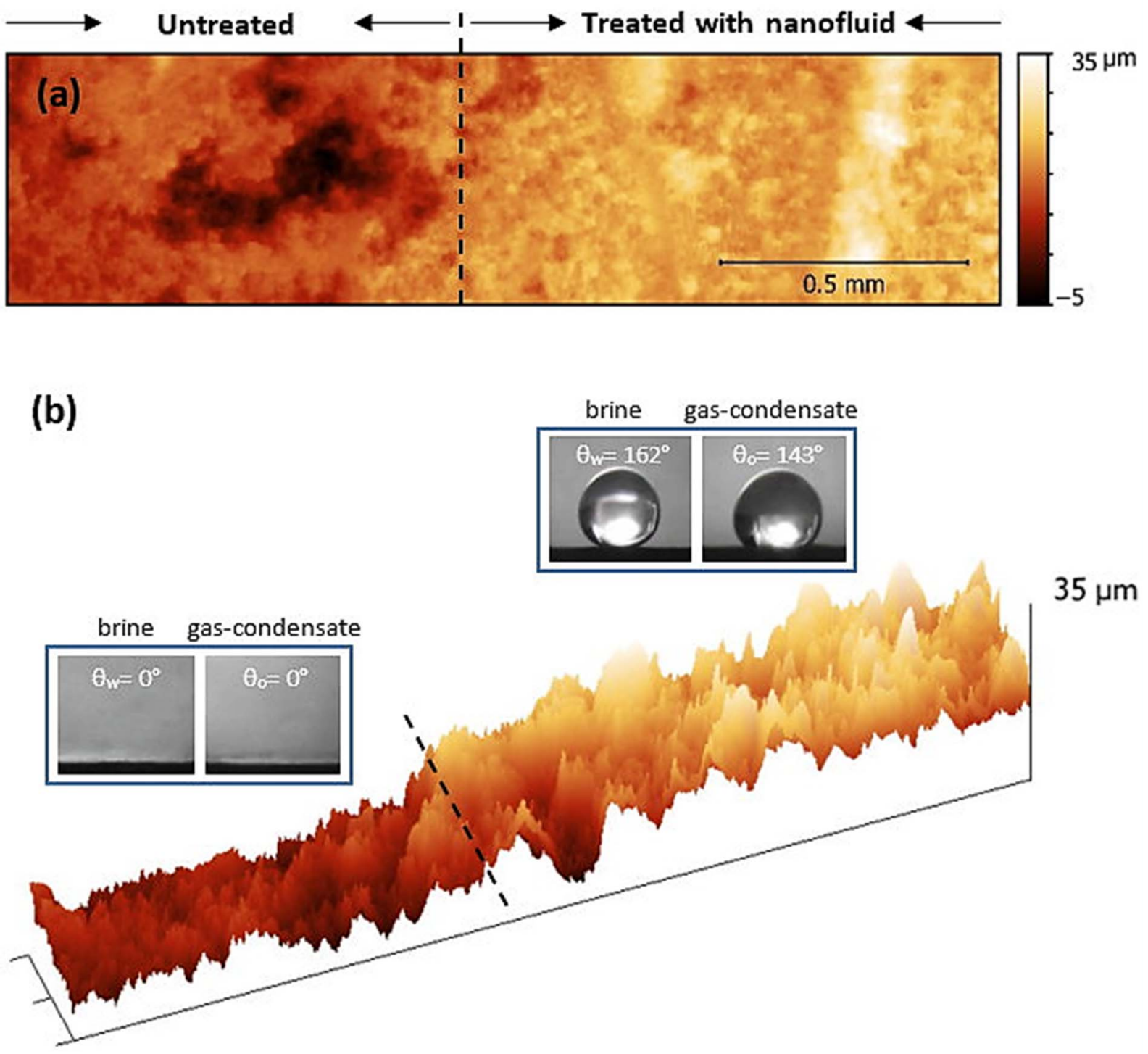

$35 \mu \mathrm{m}$

Fig. 5. (a) 2D and (b) 3D SP micrographs for the prepared untreated/treated core substrate. Inset in image (b) are cross-sectional view of brine and gas-condensate drops located on both untreated and treated part of the core surface.

initial wettability, while the oil phase repellency for a strongly oil-wet core is slightly less than a strongly waterwet core. Therefore, the superamphiphobic $\mathrm{TiO}_{2}$ nanofluid is capable of altering the wettability of both water-wet and oil-wet carbonate core plug to ultra gas-wet state.

\subsection{Coreflooding}

Figure 6 displays the measured gas/water and gas/oil relative permeabilities for the untreated and treated core sample CC- 1 at $80^{\circ} \mathrm{C}$ and $\Delta p^{*}$ (the sufficiently high injection pressure gradient to minimize the capillary end-effect) using an unsteady state displacement approach. Based on the core displacement results for gas/water system, the relative permeabilities of both the gas and water phase were increased significantly after wettability alteration from strongly water-wetting to gas-wetting (Fig. 6a). The residual water saturation by gas flooding reduced from 0.53 to
0.24 PV. Relative permeability of the gas phase at the residual water saturation enhanced about two times owing to the alteration of wettability to gas-wetting. The water saturation at the cross point $\left(K_{\mathrm{rg}}=K_{\mathrm{rw}}\right)$ decreased from 0.71 to $0.6 \mathrm{PV}$ and the cross point relative permeability increased from 0.16 to 0.37 , demonstrating an improvement of two-phase flow mobility. The trend of the results is in agreement with the work of Li et al. [13].

For gas/oil system, the influence of wettability alteration on relative permeability of gas and oil showed a similar trend to that measured for gas and water relative permeabilities (Fig. 6b). The residual oil saturation after gas flooding decreased from 0.49 to $0.19 \mathrm{PV}$. At the residual oil saturation, the gas phase relative permeability improved dominantly due to wettability alteration from strongly oilto gas-wetness. The oil saturation at cross point reduced from 0.71 to 0.58 and the cross point relative permeability raised from 0.19 to 0.36 too. 

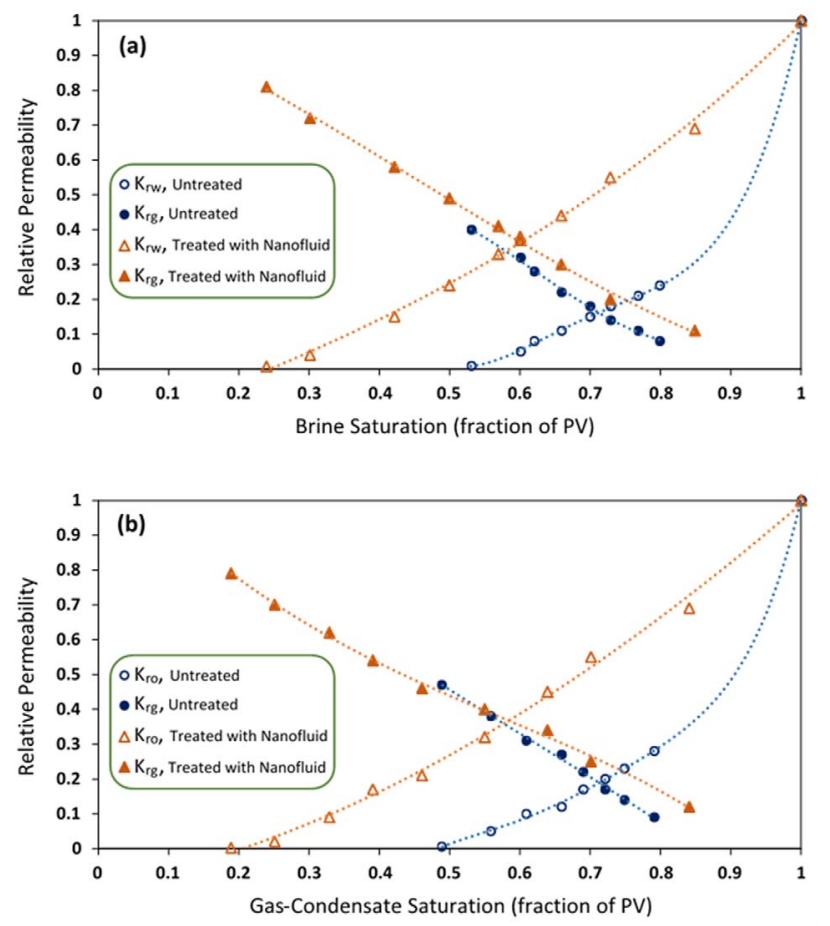

Fig. 6. (a) Gas-water and (b) gas-oil relative permeabilities measured for treated and untreated carbonate core at $\Delta p^{*}$.

Figure 7 shows the results of water and oil recovery by gas flooding in a gas/water and gas/oil system, respectively, before and after the change of wettability. The recovery of both water and oil increased predominantly after the wettability alteration of the core by the $\mathrm{TiO}_{2}$ nanofluid treatment. The value of ultimate water and oil recovery by gas flooding is increased about $38 \%$ and $36 \%$ after the wettability alteration, respectively. Accordingly, the more production of liquid after wettability alteration to gas-wetting implies that the water and/or oil would not accumulate in rock pores to block the flow of gas, hence the more gas could then be produced.

The capillary end-effect problem is one of the most considerable concerns in coreflooding experiments, especially for the case that the core length is very short. The models which are applied to interpret the dynamic displacement data in unsteady state flooding experiments, such as the Toth method, assume that the influence of capillary pressure on saturation distribution is negligible. Hence, when the boundary effect is significant, it leads to errors in calculation of saturation and subsequently the relative permeability from production data. In this case, the obtained results from these experiments are not very reliable. As stated earlier, a high pressure gradient for injection of nitrogen was applied to overcome the capillary end-effect in the core. In order to show better the effect of pressure gradient on relative permeabilities, we repeated the coreflooding experiments using different injection pressure gradients and then compared the resulting relative permeability curves with the existing ones measured at $\Delta p^{*}$.
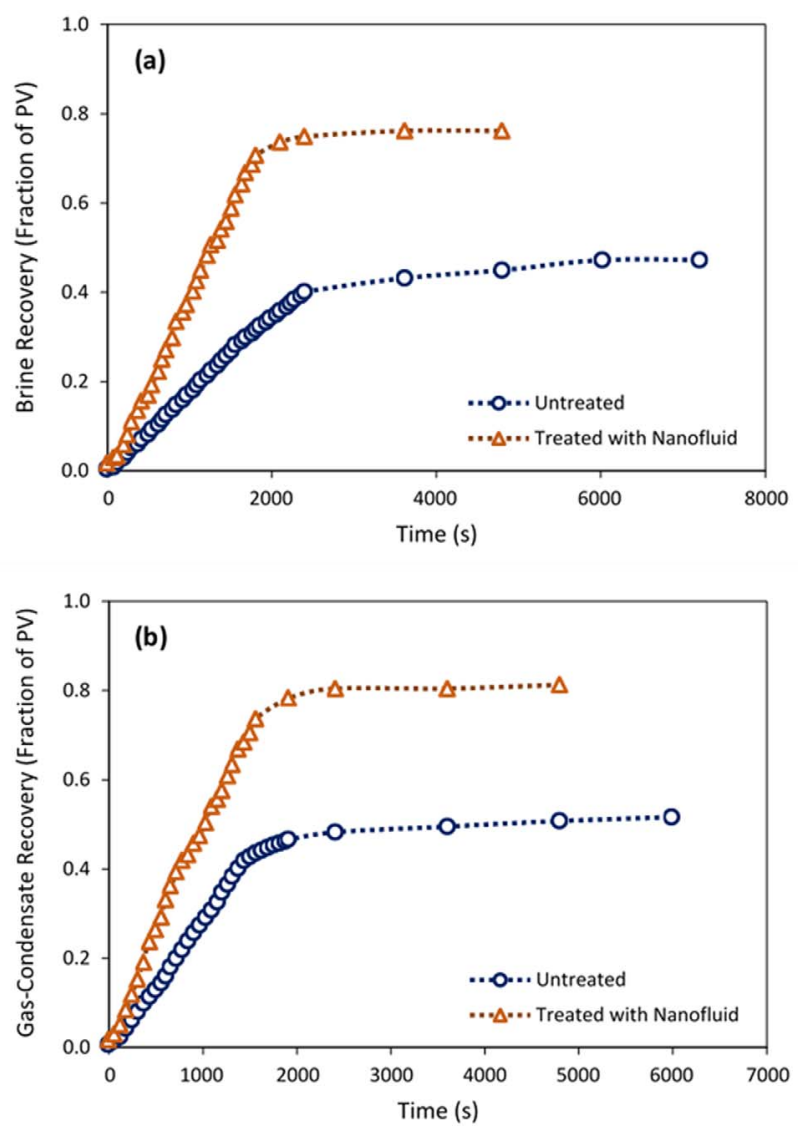

Fig. 7. (a) Water and (b) oil recovery measured with and without wettability alteration to gas-wetness.

Figure 8 illustrates the measured gas/oil relative permeabilities for the treated core sample at different injection pressure gradients. As it is evident from the figure, the relative permeabilities of gas and oil increased with promotion of the pressure gradient. The residual oil saturation in low pressures is much higher than in high pressures, which can be allocated to the capillary end-effect. This phenomenon results in an additional saturation of oil at the end of the core. Therefore, the oil saturation increases at the end of the gas flooding experiment and subsequently affects the relative permeability curves. In high pressures gradients the capillary end-effect is lower because the viscous forces are greater than the capillary forces. Hence, more pores drain during the gas flooding, the oil residual saturation reduced and the relative permeabilities of both gas and oil increase.

\subsection{Effect of initial gas-condensate liquid saturation on the treatment efficiency}

\subsubsection{Spontaneous imbibition}

The spontaneous imbibition of water or n-decane into a dry, air-saturated carbonate rock, before and after wettability alteration of the rock to gas-wetting condition by $\mathrm{TiO}_{2}$ nanofluid was measured in our previous paper [18]. We have 

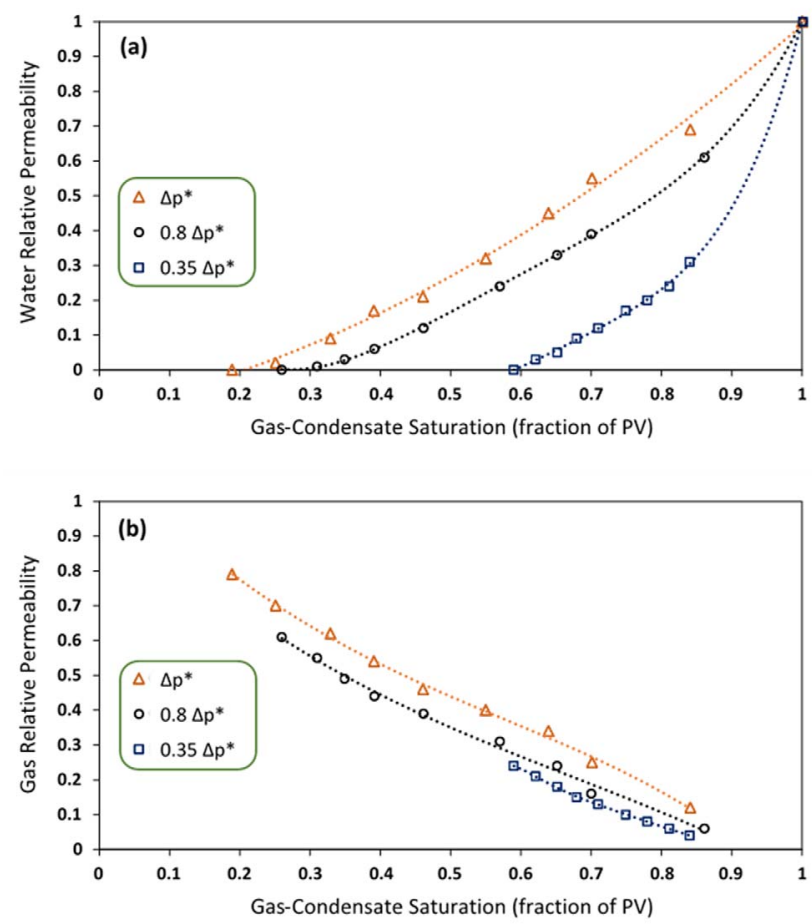

Fig. 8. (a) Oil and (b) gas relative permeabilities measured for treated carbonate core at various pressure gradients.

showed that the final saturations of water and n-decane imbibed in the air-saturated rock sample reduced predominantly after wettability alteration. Here, the spontaneous imbibition test was conducted to study the impact of wettability alteration to gas-wetting state on gas-condensate recovery in a carbonate rock initially saturated with gascondensate. Figure 9 depicts the result of spontaneous imbibition test of nanofluid into the core sample CC-2 saturated with gas-condensate liquid. Since the designed $\mathrm{TiO}_{2}$ nanofluid is ethanol-based, the result is compared with the result of similar test using ethanol as the imbibing fluid. As it is seen in the figure, very small amount of oil has been produced by ethanol at the end of the test. This small amount of recovered oil is equal to $5 \%$ Original Oil In Place (OOIP). $\mathrm{TiO}_{2}$ nanofluid, however, imbibed predominantly into the core sample, resulting in considerable ultimate oil recovery of about $34.7 \%$. The reduction in gas-condensate saturation of the core indicates that the imbibed amount of nanofluid could successfully change the wettability of the core to gaswetting condition. Deductively, occurrences of the similar phenomenon in a gas condensate reservoir lead to decreasing of the condensate accumulation around the wellbore and increasing of the gas-condensate recovery from the production well.

\subsubsection{Relative permeability of gas/oil system}

The saturation of liquid condensate dropout in the near wellbore region of gas condensate reservoirs can reach $40-60 \%[36,37]$. Therefore, the presence of gas-condensate

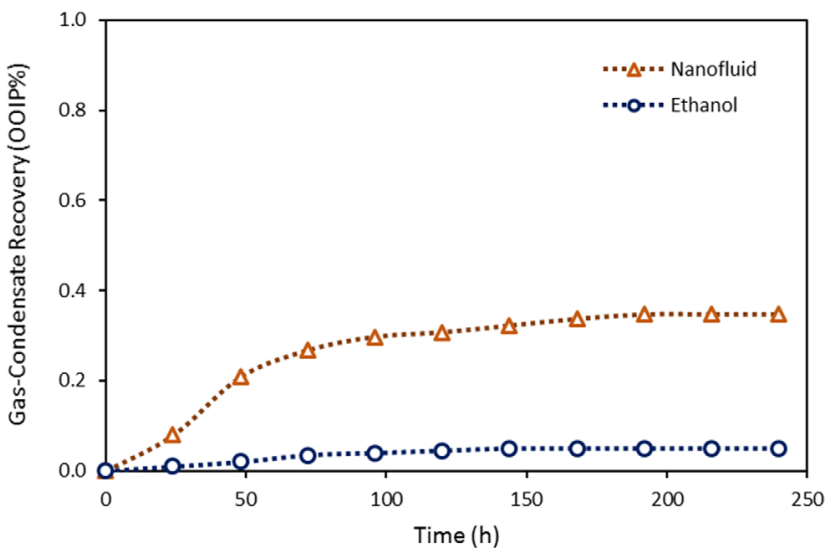

Fig. 9. Spontaneous imbibition of $\mathrm{TiO}_{2}$ nanofluid into oil-wet gas-condensate saturated core.
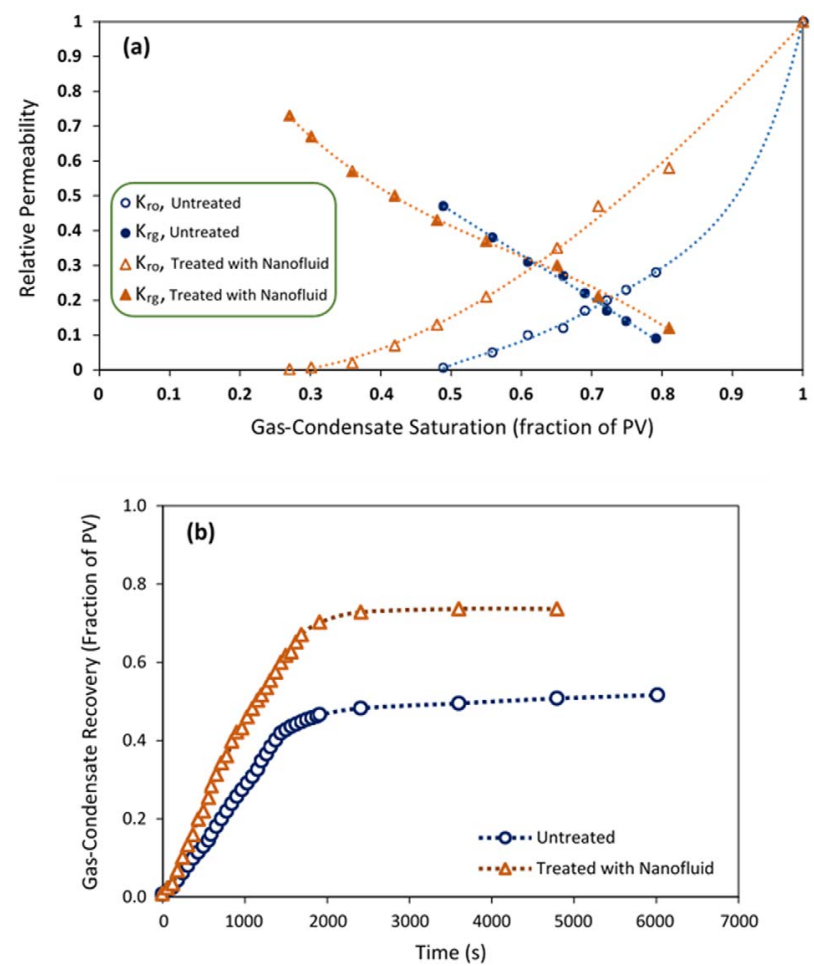

Fig. 10. (a) Gas-oil relative permeability and (b) oil recovery measured for treated and untreated oil-wet carbonate core at $\Delta p^{*}$.

might affect the efficiency of core treatment by nanofluid. To study the case and evaluate its effects on gas and oil relative permeabilities in a gas/oil system, we investigated a new treatment process with one difference comparing to what we have earlier described in Section 2.6. In this process, in order to alter the wettability of the core to gas-wetness with $\mathrm{TiO}_{2}$ nanofluid we treated the oil-wet 
gas-condensate saturated core (wet core) instead of treating the water-wet dry core. The remaining procedure of the core treatment were the same. Next, the full gas-condensate saturation was re-established in the core before it was used for coreflooding test. According to the obtained results from the core displacement test, either of the gas and oil relative permeabilities were increased interestingly after wettability alteration (Fig. 10a). The residual oil saturation by gas flooding decreased from 0.49 to $0.27 \mathrm{PV}$. The oil saturation at $K_{\mathrm{rg}}=K_{\mathrm{ro}}$ decreased from 0.71 to $0.61 \mathrm{PV}$ and relative permeability at the cross point increased from 0.19 to about 0.3. Moreover, the final recovery of oil after gas flooding increased about $30 \%$ after the wettability alteration (Fig. 10b). It can be deduced from these results that during the treatment process, the $\mathrm{TiO}_{2}$ nanofluid imbibed effectively into the core and successfully altered the wettability of the core to gas-wetting (as described in Sect. 3.4.1).

Comparing the results of coreflooding test for the core with and without initial gas-condensate saturation before the treatment process reveals that the final oil recovery by gas flooding for the core with initial oil saturation is $6 \%$ less than the oil recovery for the core without initial oil saturation. Therefore, the initial presence of gas-condensate in the core slightly reduces the efficiency of nanofluid for changing the wettability of the core toward gas wetting.

\section{Conclusion}

The wettability of carbonate reservoir rock is changed from liquid-wetting to ultra gas-wetting when treated with the superamphiphobic nanofluid consisted of synthesized superhydrophobic $\mathrm{TiO}_{2}$ nanoparticles and fluorochemicals as PTFE and PFOS mixture. The contact angle measurements indicated the capability of nanofluid in alteration of wettability from both strongly water- and oil-wetting state to ultra gas-wetting condition. Surface characterizations of the treated core plugs were carried out by SEM and SP analyses. Accordingly, the ultra gas-wetting is attributed to the combined effect of roughness created by adsorption of nanoparticles on the microscale structure of rock surface and low surface energy of fluoro-containing materials. The use of $\mathrm{TiO}_{2}$ nanofluid in free imbibition into the oil-wet gas-condensate saturated core plug demonstrated the strong capability of the nanofluid for oil recovery from gas condensate reservoirs. Core displacement tests also confirmed that the $\mathrm{TiO}_{2}$ nanofluid could be applied for wettability alteration to gas-wetting in reservoir conditions and solving the problem of condensate/water blockage regarding the following results: After wettability alteration to gas-wetting for both gas/oil and gas/water system (1) both liquid and gas phase mobility increased significantly; (2) the residual saturation of liquid phase in porous media decreased by gas flooding; and (3) the liquid phase recovery and gas production increased predominantly.

Acknowledgments. The authors gratefully acknowledge Dr. Matthias Menzel from Fraunhofer Institute for Microstructure of Materials and Systems IMWS, Halle (Germany) for conducting SP experiments. We do also thank Dr. Pegah Esmaeilzadeh and Dr. Stefan L. Schweizer from Martin Luther University Halle-Wittenberg of Germany for their considerable helps with the SP analyses.

\section{References}

1 Afidick D., Kaczorowski N.J., Bette S. (1994) Production performance of a retrograde gas reservoir: a case study of the Arun Field, SPE Asia Pacific Oil and Gas Conference, Melbourne, Australia.

2 El-Banbi A., McCain W.D., Semmelbeck M.E. (2000) Investigation of well productivity in gas-condensate reservoirs, SPE/CERI Gas Technology Symposium, Calgary, Canada.

3 Garzon F.O., Al-Anazi H.A., Leal J.A., Al-Faifi M.G. (2006) Laboratory and field trial result of condensate banking removal in retrograde gas reservoirs: case history, SPE Annual Technical Conference $\&$ Exhibition, San Antonio, USA.

4 Al-Anazi H.A., Walker J.G., Pope G.A., Sharma M.M., Hackney D.F. (2005) A successful methanol treatment in gascondensate reservoir: field application, SPE Prod. Facil. J. 20, 60-68.

5 Li K., Firoozabadi A. (2000) Experimental study of wettability alteration to preferential gas-wetting in porous media and its effects, SPE Reserv. Evalu. Eng. 3, 139-149.

6 Tang G.Q., Firoozabadi A. (2002) Relative permeability modification in gas/liquid systems through wettability alteration to intermediate gas wetting, SPE Reserv. Evalu. Eng. 5, 427-436.

7 Tang G.Q., Firoozabadi A. (2003) Wettability alteration to intermediate gas-wetting in porous media at elevated temperatures, Transp. Porous Media 52, 185-211.

8 Fahes M., Firoozabadi A. (2007) Wettability alteration to intermediate gas-wetting in gas condensate reservoirs at high temperatures, SPE J. 12, 397-407.

9 Noh M., Firoozabadi A. (2008) Wettability alteration in gas-condensate reservoirs to mitigate well deliverability loss by water blocking, SPE Reserv. Evalu. Eng. 11, 676-685.

10 Kumar V., Bang V., Pope G.A., Sharma M.M., Ayyalasomayajula P.S., Kamath J. (2006) Chemical stimulation of gas/condensate reservoirs, SPE Annual Technical Conference $\&$ Exhibition, San Antonio, USA.

11 Kumar V., Pope G.A., Sharma M.M. (2006) Improving the gas and condensate relative permeability using chemical treatment, SPE Gas Technology Symposium, Calgary, Canada.

12 Xie X., Liu Y., Sharma M., Weiss W.W. (2009) Wettability alteration to increase deliverability of gas production wells, $J$. Nat. Gas Sci. Eng. 1, 39-45.

13 Li K., Liu Y., Zheng H., Huang G., Li G. (2011) Enhanced gas-condensate production by wettability alteration to gas wetness, J. Petrol. Sci. Eng. 78, 505-509.

14 Feng C., Kong Y., Jiang G., Yang J., Pu C., Zhang Y. (2012) Wettability modification of rock cores by fluorinated copolymer emulsion for the enhancement of gas and oil recovery, Appl. Surf. Sci. 258, 7075-7081.

15 Sharifzadeh S., Hassanajili S., Rahimpour M.R. (2012) Wettability alteration of gas condensate reservoir rocks to gas wetness by sol-gel process using fluoroalkylsilane, J. Appl. Polym. Sci. 128, 4077-4085. 
16 Mousavi M., Hassanajili S., Rahimpour M.R. (2013) Synthesis of fluorinated nano-silica and its application in wettability alteration near-wellbore region in gas condensate reservoirs, Appl. Surf. Sci. 273, 205-214.

17 Aminnaji M., Fazeli H., Bahramian A., Gerami S., Ghojavand H. (2015) Wettability alteration of reservoir rocks from liquid wetting to gas wetting using nanofluid, Transp. Porous Media 109, 201-206.

18 Esmaeilzadeh P., Sadeghi M.T., Fakhroueian Z., Bahramian A., Norouzbeigi R. (2015) Wettability alteration of carbonate rocks from liquid-wetting to ultra gas-wetting using $\mathrm{TiO}_{2}$, $\mathrm{SiO}_{2}$ and CNT nanofluids containing fluorochemicals, for enhanced gas recovery, J. Nat. Gas Sci. Eng. 26, 1294-1305.

19 Hwang Y., Lee J., Lee J., Jeong Y., Cheong S., Ahn Y., Kim S. (2008) Production and dispersion stability of nanoparticles in nanofluids, Powder Technol. 186, 145-153.

20 Ghadimi A., Saidur R., Metselaar H. (2011) A review of nanofluid stability properties and characterization in stationary conditions, Int. J. Heat Mass Transfer 54, 4051-4068.

21 Yang Y., Oztekin A., Neti S., Mohapatra S. (2012) Particle agglomeration and properties of nanofluids, J. Nanopart. Res. 14, 1-10.

22 Lokwani D.B., Rathod P.P., Markana J.H., Shah N.A. (2015) Experimental Investigation on $\mathrm{TiO}_{2} \mathrm{Nano}$ Fluid Preparation and its Properties, Int. J. Adv. Res. Eng. Sci. Technol. 2, 2394-2444.

23 Muthiah P., Bhushan B., Yun K., Kondo H. (2013) Duallayered-coated mechanically-durable superomniphobic surfaces with anti-smudge properties, J. Colloid Interface Sci. 409, 227-236.

24 Toth J., Bodi T., Szucs P., Civan F. (2002) Convenient formulae for determination of relative permeability from unsteady-state fluid displacements in core plugs, J. Petrol. Sci. Eng. 36, 33-44.

25 Nosonovsky M., Bhushan B. (2009) Superhydrophobic surfaces and emerging applications: Non-adhesion, energy, green engineering, Curr. Opin. Colloid Interface Sci. 14, 270-280.
26 Hsieh C.T., Wu F.L., Chen W.Y. (2010) Superhydrophobicity and superoleophobicity from hierarchical silica sphere stacking layers, Mater. Chem. Phys. 121, 14-21.

27 Celia E., Darmanin T., Givenchy E.T., Amigoni S., Guittard F. (2013) Recent advances in designing superhydrophobic surfaces, J. Colloid Interface Sci. 402, 1-18.

28 Valipour Motlagh N., Birjandi F.C., Sargolzaei J. (2014) Super-non-wettable surfaces: A review, Colloids Surf. A Physicochem. Eng. Aspects 448, 93-106.

29 Cassie A.B.D., Baxter S. (1994) Wettability of porous surfaces, Trans. Faraday Soc. 40, 546-551.

30 Song H.J., Zhang Z.Z., Men X.H. (2008) Superhydrophobic PEEK/PTFE composite coating, Appl. Physics A 91, 73-76.

31 Im M., Im H., Lee J.H., Yoon J.B., Choi Y.K. (2010) A robust superhydrophobic and superoleophobic surface with inversetrapezoidal microstructures on a large transparent flexible substrate, Soft Matt. 6, 1401-1404.

32 Shibuichi S., Yamamoto T., Onda T., Tsujii K. (1998) Super water- and Oil-repellent surfaces resulting from fractal structure, J. Colloid Interface Sci. 208, 287-294.

33 Xie Q., Xu J., Feng L., Jiang L., Tang W., Luo X., Han C.C. (2004) Facile creation of a super-amphiphobic coating surface with bionic microstructure, Adv. Mat. 16, 302-305.

34 Nishino T., Meguro M., Nakamae K., Matsushita M., Ueda Y. (1999) The lowest surface free energy based on $-\mathrm{CF}_{3}$ alignment, Langmuir 15, 4321-4323.

35 Barthwal S., Kim Y., Lim S.H. (2013) Fabrication of amphiphobic surface by using titanium anodization for large-area three-dimensional substrates, J. Colloid Interface Sci. 400, 123-129.

36 Whitson C.H., Fevang Ø., Yang T. (1999) Gas condensate PVT - what's really important and why? IBC Conference Optimization of Gas Condensate Fields, England, London.

37 Tweheyo M.T., Holt T., Torsæter O. (1999) An experimental study of the relationship between wettability and oil production characteristics, J. Petrol. Sci. Eng. 24, 179-188. 


\section{Appendix}

The Toth method is used for calculation of relative permeability from unsteady state, two-phase fluid displacement in cores under constant pressure condition. The advantage of this method is that the produced displaced and displacing fluid volumes versus time is enough for determination of wetting phase saturation and subsequently the relative permeabilities. The procedure is explained as following:

The produced displaced (water or oil) and displacing (gas) fluid volume $\left(V_{k}\right.$ and $\left.V_{d}, \mathrm{~cm}^{3}\right)$ after breakthrough and the cumulative injected fluid volume $\left(V_{i}, \mathrm{~cm}^{3}\right)$ can be correlated by equation (A.1) which is a general linear relationship:

$$
\frac{V_{i}(t)}{V_{k}}=a+b\left(\frac{V_{i}(t)}{V_{p}}\right) ; \quad\left(t \geq t_{a}\right)
$$

where $t_{a}$ is the breakthrough time and $a, b$ are dimensionless empirical constants.

By founding the $a$ and $b$ constants, the fractional displacing and displaced fluid flows $\left(f_{d}, f_{k}\right)$ are determined using the following expressions, respectively:

$$
\begin{gathered}
f_{d}=\frac{q_{d}}{q_{i}}=1-f_{k} \\
f_{k}=\frac{q_{k}}{q_{i}}=\frac{a}{\left(a+b\left(\frac{V_{i}(t)}{V_{p}}\right)\right)^{2}}
\end{gathered}
$$

Also, equation (A.4) is applied to express the outlet-face saturations of the displacing fluid $\left(S_{d_{2}}\right)$ as function of the injected cumulative fluid volume:

$$
S_{d_{2}}=S_{\mathrm{di}}+b\left(\frac{\frac{V_{i}(t)}{V_{p}}}{\mathrm{a}+\mathrm{b} \frac{V_{i}(t)}{V_{p}}}\right)^{2}
$$

where $S_{d i}$ is the saturation of displacing fluid in the core prior to the displacement.

A power-law equation as following is used for correlating the cumulative injected fluid volume:

$$
V_{i}(t)=a_{2} t^{b_{2}}
$$

where $a_{2}$ and $b_{2}$ are empirical constants.

Next, the total mobility function $\left(\mathrm{Y}\left(S_{d_{2}}\right)\right)$ at outlet face of the core is calculated by an equation as below:

$$
\mathrm{Y}\left(S_{d_{2}}\right)=\frac{L a_{2} b_{2}^{2}\left(\frac{V_{p}}{a_{2}}\right)^{\left(1-\frac{1}{b_{2}}\right)}}{\Delta p K A\left(2 b_{2}-1\right)}\left(\frac{V_{i}(t)}{V_{p}}\right)^{\left(1-\frac{1}{b_{2}}\right)} .
$$

where $L$ is the core length $(\mathrm{cm}), A$ is cross-section area of the core $\left(\mathrm{cm}^{2}\right), \Delta p$ is pressure difference (bar) and $K$ is the core absolute permeability $\left(\mathrm{cm}^{2}\right)$.

Consequently, the relative permeability of displacing and displaced fluids are determined conveniently as function of viscosity $(\mu, \mathrm{cP})$, fractional fluid flow $(f)$ and the total mobility function $\mathrm{Y}\left(S_{d_{2}}\right)$ using the following equations, respectively:

$$
\begin{gathered}
K_{r d}=\mu_{d} \frac{M_{d_{2}} \mathrm{Y}\left(S_{d_{2}}\right)}{M_{d_{2}}+1}=\mu_{d} f_{d} \mathrm{Y}\left(S_{d_{2}}\right) \\
K_{r k}=\mu_{k} \frac{\mathrm{Y}\left(S_{d_{2}}\right)}{M_{d_{2}}+1}=\mu_{k} f_{k} \mathrm{Y}\left(S_{d_{2}}\right)
\end{gathered}
$$

